\title{
Non-invasive voiding assessment in conscious mice
}

Martin Sidler ${ }^{1,2,3,4 *}$, Karen J. Aitken ${ }^{1}$, Sarah Forward ${ }^{5}$, Alex Vitkin ${ }^{5}$, Darius J. Bagli ${ }^{1,2,3}$

\section{Supplemental Figure 1}

Macro code for visual basic editor in Excel $^{\circledR}$

Sub detect_and_calculate_mict_volume

'detects micturition based on increase of max value and provided previous line was NOT a micturition

Range("J28:J700").Formula = "=IF((average(128:129)-

average(125:I27)>=\$B\$17)*AND(SUM(J25:J27)=0)*AND((average(129:|31)-average(138:I40))>=\$B\$20),1,0)"

'edits actual micturition volume

Range("K28:K700").Formula = "=IF(J28=1,(AVERAGE(I29:I33)-AVERAGE(I24:I27)), )"

End Sub

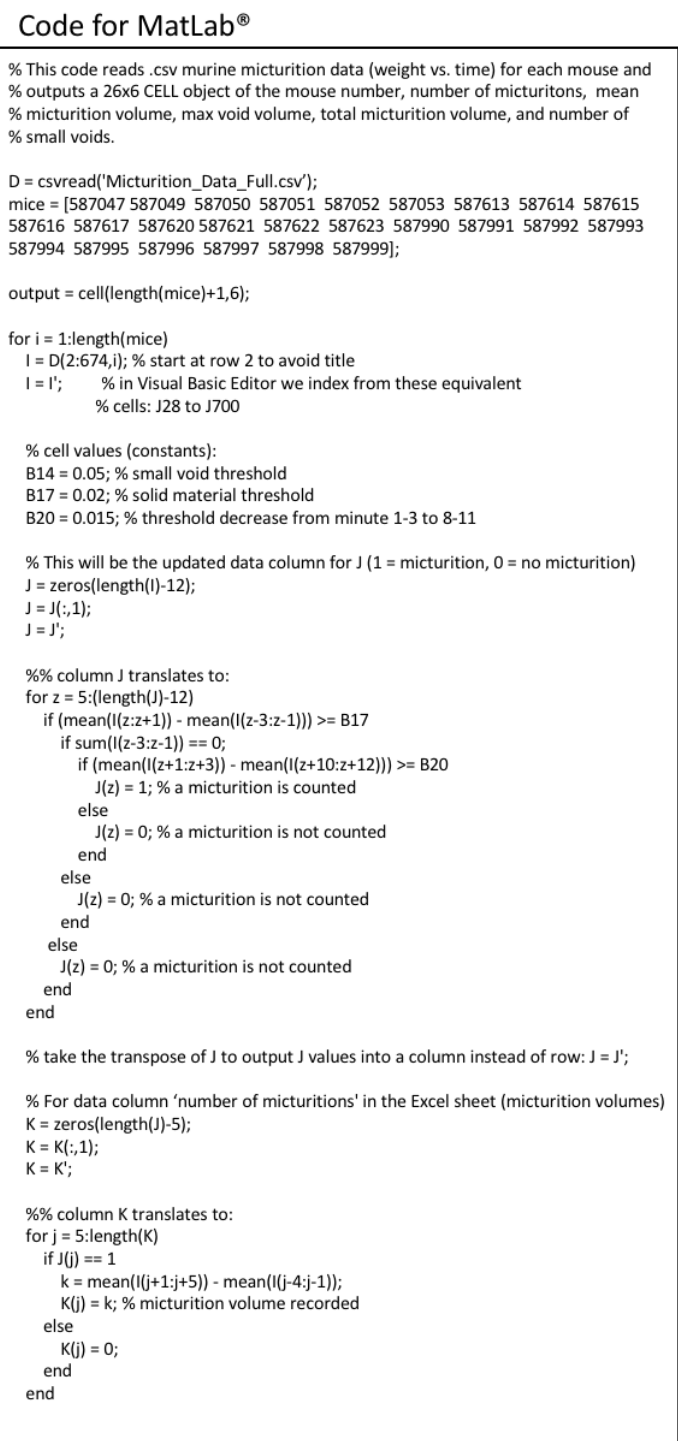

\% take the transpose of $\mathrm{K}$ to output $\mathrm{K}$ values into a column instead of row: $\mathrm{K}=\mathrm{K}^{\prime}$;

\% This algorithm avoids double counting if there are two mass increases right $\%$ beside each other

for $j=1$ :(length $(K)-1)$

if $j<=60 \%$ begin recording micturitions after 60 minutes
Kang

$\mathrm{K}(\mathrm{j})=0$;

end $\quad$ if $K(j)>0 \& \& K(j+1)>0$

$\% \quad K(j+1)=0$

end

$\% \%$ Total number of micturitions

count $=0$;

count $=0$;
for $j=1$ :length $(K)$

if $\mathrm{K}(\mathrm{i})>0$

count $=$ count +1 ;

end

$\% \%$ Total micturition volume

volumes $=[$ ];

for $j=1$ :length $(K)$

if $\mathrm{K}(\mathrm{V})>0$

volumes $=[$ volumes, $\mathrm{K}(\mathrm{j})]$;

end

end
$\% \%$

if isempty(volumes)

volumes $=0$;

end

$\% \%$ Number of small voids

small_voids $=0$;

for $j=1$ :length $(K)$

if $K(j)>0$

if $K(j)<=B 14$

small_voids $=$ small_voids +1

end

end
end

$\% \%$

$\% \%$

output $\{1,2\}=$ '\# of Ms';

output $\{1,3\}=$ 'Mean M volume',

output $\{1,4\}=$ ' 'Max void';

output $\{1,5\}=$ 'Total $\mathrm{M}$ volume'

output $\{1,6\}=$ = '\# of small voids';

output $\{i+1,1\}=$ num 2 str(mice(i));

output $\{i+1,2\}=$ count:

output $\{i+1,3\}=$ mean(volumes);

output $\{1+1,4\}=\max$ (volumes);

output $(i+1,6)=$ small_voids;

end

disp(' $M$ = micturition')

disp(output)

Figure S1. Macro code for visual basic editor in Excel and code for MatLab ${ }^{\circ}$. 